Oksana Rabczun

Kijów

\title{
Książki Stanisława Orzechowskiego w zbiorach Oddziału Kolekcji Bibliotecznych i Historycznych Narodowej Biblioteki Ukrainy im. W. I. Wernadskiego
}

W zbiorach Oddziału Kolekcji Bibliotecznych i Historycznych (Відділ бібліотечних зібрань та історичних колекцій - dalej WBZIK) Narodowej Biblioteki Ukrainy im. W. J. Wernadskiego (dalej NBUW) zachowało się kilkanaście druków dzieł Stanisława Orzechowskiego h. Oksza (1513-1566), znanego pisarza politycznego i polemisty religijnego, którego 500 rocznicę urodzin obchodzono w listopadzie 2013 roku. Warto wspomnieć, że wśród zgromadzonych w kijowskich zbiorach egzemplarzy są zarówno prace wydane za życia autora, jak i pośmiertnie w XVIIXIX w. Zasób WBZIK tworzy ponad 80 odrębnych kolekcji książkowych - zbiorów historyczno-kulturowych, które w różnych okresach trafiły do NBUW. Kolekcje te różnią się zarówno ilościąjak i jakością zachowanych druków. Historyczny zasób tworzą księgozbiory poklasztorne z okresu przedrewolucyjnego, biblioteki szkół średnich i wyższych działających na terenie Imperium Rosyjskiego. Wśród tych ostatnich znaleźć można prywatne księgozbiory znanych działaczy państwowych i ludzi związanych z ówczesną kulturą. Do kolekcji włączone zostały także czasopisma religijne i świeckie a także zbiory specjalne obejmujące najstarsze druki pochodzące $z$ lat 1500-1550 oraz Biblie.

Prace S. Orzechowskiego zostały wyodrębnione m.in. z katalogu literatury polskiej (sześć z nich wydano za życia autora) a także z katalogów innych bibliotek, np. Uniwersytetu św. Włodzimierza. W trakcie poszukiwań natrafiono na pięć druków S. Orzechowskiego pochodzących z biblioteki króla polskiego Stanisława Augusta Poniatowskiego (sygnatura Reg. X.), z czego jeden egzemplarz wydany był jeszcze za życia autora. 
Trzy prace trafiły do kijowskich zbiorów z „Nowej kolekcji” biblioteki Liceum Krzemienieckiego; trzy z kolekcji rodzinnej Jabłonowskich, dwa z kolekcji Urbanowskich i Starzyńskich, dwa z biblioteki Uniwersytetu św. Włodzimierza (cześć „ROKY”), po jednym z bibliotek Wiśniowieckich i Mniszchów na zamku w Wiśniowcu, kolekcji klasztoru karmelitów bosych w Berdyczowie, jezuickiego w Krzemieńcu oraz z biblioteki Ławry Kijowsko-Pieczerskiej. Dwa wydania osiemnastowieczne udało się odszukać w Bibliotece Uniwersytetu św. Włodzimierza (część „ROKY”) oraz w zbiorach biblioteki Ławry Kijowsko-Pieczerskiej.

Analiza miejsc w których znajdowały się wymienione biblioteki przed ich włączeniem do NBUW pokazuje, że prawie wszystkie (poza biblioteką Uniwersytetu św. Włodzimierza i Ławry Kijowsko-Pieczerskiej) znajdowały się na terenie obecnych obwodów: wołyńskiego, tarnopolskiego i chmielnickiego. Oczywiście nie odnosi się to do XIX-wiecznych wydań dzieł Orzechowskiego. Poniżej zostanie przedstawiony katalog zachowanych w WBZIK NBUW druków dzieł Orzechowskiego w kolejności chronologicznej wydań.

1. Listy Stanisława Orzechowskiego, w ktorych, ktory iest prawdziwy Koscioł, od Krystusa y od Apostołow postanowiony dostatecznie a mądrze naprzeciwko nowym Ewanyelikom dowodzi... - [Kraków: Łazarz Andrysowic, po 1 V 1561]. - [36, ost. cz.] k.; 8. K. Estreicher, Bibliografia polska (dalej cyt.: Estr.) t. 23, s. 451. Sygnatura: Cr. 4154.

Egzemplarz zachowany w dość dobrym stanie. Niestety przy oprawianiu ścięto nieznaczną część tekstu u góry. Oprawa kartonowa ma niewielkie uszkodzenia. Na wyklejkach napisy po łacinie. Zdarzają się także napisy czarnym atramentem na strnie przedtytułowej oraz na stronie tytułowej dzieła (po polsku i łacinie). Na stronie przedtytułowej znajduje się owalna pieczątka koloru czerwonego z napisem „BIBLIOTECA UNIVERSITATIS St. WLADIMIRI".

2. Stanislai Orichovii Roxolani, Chimaera: Sive De Stancari Fvnesta Regno Poloniae secta... - [Kraków: Łazarz Andrysowic], 1562. - [8], 1 tabl., 104, [6] k., il.; 4º. Estr., t. 23, s. 446-447.

\section{Egz. a: Sygnatura: Reg. X. 66a}

Egzemplarz ma oprawę kartonowa, grzbiet oraz rogi okładki są skórzane. Na wyklejce napis ołówkiem z sygnaturą książki. Na stronie tytułowej owalna pieczątka koloru fioletowego z napisem „Библиотека университета Св. Владимира" (Biblioteka Uniwersytetu św. Włodzi- 
mierza). Egzemplarz posiada znaczną ilością notatek na marginesach (niemal nieczytelne). Książka była restaurowana - podklejano od tyłu stronę tytułową.

\section{Egz. b: Sygnatura: Pol.XVI B 18.}

Egzemplarz ma oprawę kartonowa, grzbiet i rogi okładki są skórzane. $\mathrm{Na}$ grzbiecie złote tłoczenia - imię i nazwisko autora, pierwsze słowo tytułu oraz rok wydania. Oprawa pochodzi z XIX w. Blok barwiony na kolor żółty. Na wyklejce napisana ołówkiem sygnatura. Oprócz niej na wyklejce znajdują się także zapiski czarnym atramentem, które przypominaja jakieś obliczenia. Na stronie tytułowej napisy po łacinie zrobione czarnym atramentem. Zdarzają się również nieliczne zapiski na marginesach. Na niektórych stronach książki zauważalne ślady wilgoci.

\section{Egz. c: Sygnatura: Pol.XVI B 58.}

Egzemplarz ma kartonową oprawę, grzbiet i rogi okładki są skórzane. Na grzbiecie złote tłoczenia - imię i nazwisko autora, pierwsze słowo tytułu oraz rok wydania. Oprawa pochodzi z XIX w. Karta ochronna Wyklejka książki zrobiona jest z papieru ,pawie oczko”. Na karcie tytułowej napis ołówkiem - sygnatura. Na stronie tytułowej napisy, jeden z nich (na środku strony) został dokładnie zamazany, co spowodowało powstanie dziur w kartce. U dołu strony tytułowej znajduje się podpis właściciela. Egzemplarz posiada nieliczne notatki na marginesach.

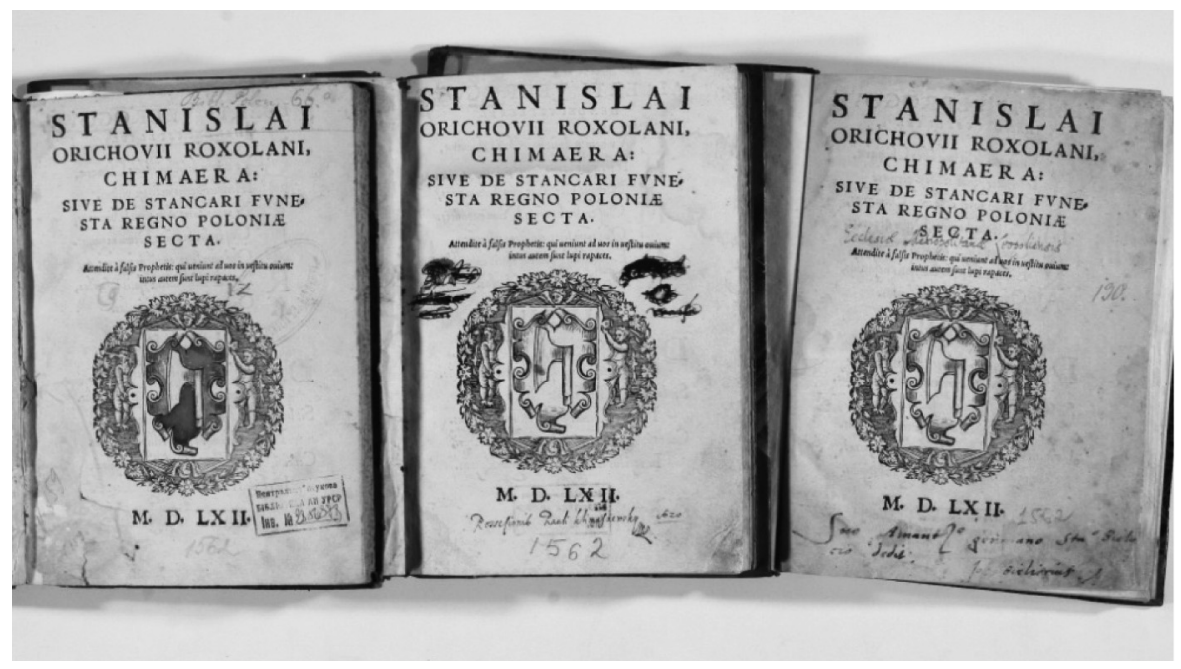


3. Stanislai Orichovii Roxolani, Chimaera: Sive De Stancari funesta Regno Poloniae Secta... - Coloniae: apud Maternum Cholinum, typ. God. Cervicorni, 1563. - [12], 170, [5] k.; 8. Estr., t. 23, s. 447. Sygnatura: 3ax. XVI A 24 (№ 642 н. к.).

Egzemplarz oprawiony w skórę. Na grzbiecie papierowe naklejki z nazwiskiem autora i tytułem dzieła, jak również z sygnatura.. Kilka różnych sygnatur umieszczono na wyklejce woluminu: czarnym atramentem , «№ 642 н. к.”, czerwonym ołówkiem „3ax. XVI A 24”, czarnym atramentem „C 92”, „121” i „№ 468”. Świadczy to o tym, że egzemplarz wiele razy zmieniał właścicieli i w każdej bibliotece miał inne sygnatury. Na stronie tytułowej znajdują się zapiski czarnym atramentem, niemal zupełnie wyblakłe. Na ostatnich trzech stronach tekstu również widać notatki zrobione czarnym atramentem, prawie nieczytelne.

4. Quincunx, tho iest wzor Korony Polskiey na cynku wystawiony przez Stanisława Orzechowskiego y za kolędę posłom koronnym do Warszawy na nowe lato roku pańskiego 1564 posłany. - [Kraków: Łazarz Andrysowic], 1564. - [98, ost. cz.], 3 tabl.; 4º Estr., t. 23, s. 455-456. Sygnatura: Cr. 1919.

Egzemplarz ma miękką oprawę papierową koloru żółtego. Na grzebiecie znajduje się naklejka $\mathrm{z}$ tytułem i nazwiskiem autora. Na wyklejce napis niebieskim ołówkiem z sygnaturą książki. Na stronie przedtytułowej zapiski czarnym atramentem po polsku, dwoma różnymi charakterami pisma. Na ostatniej stronie tekstu dwie pieczątki - owalna pieczątka koloru fioletowego „Библиотека университета Св. Владимира” (Biblioteka Uniwersytetu św. Włodzimierza) oraz fioletowa prostokątna „Центральна наукова бібліотека АН УРСР” (Centralna Biblioteka Naukowa AN USRR).

5. Stanislai Orichovii Roxolani Fidelis Svbditvs Siue De Institvtione Regia ad Sigismundum Augustum Libri duo... - Cracoviae: in officina Lazari, 1584. - [1] k., 89 s.; 4º Estr., t. 23, s. 456.

\section{Egz. a: Sygnatura: BZ 7406.}

Oprawa wykonana ze skóry koloru brunatnego. Na grzbiecie czerwona naklejka z tytułem dzieła (złote tłoczenie) oraz papierowa naklejka z sygnaturą. Wyklejka koloru błękitnego. Na wyklejce znajduje się ekslibris „BIBLIOTEKA ZAHINIECKA” - oznaka przynależności do księgozbioru Urbanowskich i Starzyńskich. Blok barwiony na kolor niebieski. Stan zachowania dobry. U góry strony tytułowej, w prawym rogu napis 
„N. V”. Na ostatniej stronie tekstu okragła pieczątka koloru niebieskiego z napisem „ДЕЗ”.

\section{Egz. b: Sygnatura: Cr 1922.}

Egzemplarz ma oprawę kartonową, grzbiet i rogi okładki skórzane. $\mathrm{Na}$ grzbiecie tłoczone złote napisy - nazwisko autora i tytuł. Oprawa pochodzi z XIX w. Blok barwiony na kolor czerwony. Na wyklejce wydania znajduje się napis czarnym atramentem - sygnatura. $\mathrm{Na}$ stronie tytułowej napisy po łacinie sporządzone czarnym atramentem. Na odwrociu karty tytułowej znajduje się owalna pieczatka koloru czerwonego z napisem „BIBLIOTECA UNIVERSITATIS St. WLADIMIRI" oraz prostokatna fioletowa „Центральна наукова бібліотека АН УРСР” (Centralna Biblioteka Naukowa AN USRR).

\section{Egz. c: (def.) Sygnatura: Coll Jabl 1482}

Egzemplarz ma miękką oprawę papierową koloru błękitnego. Wolumin jest uszkodzony - widoczne są na nim ślady nadpalenia. Nie ma także części prawej górnej strony książki. Brakuje części tekstu (po str. 74). Na stronie tytułowej napisana ołówkiem sygnatura.

6. Annales Stanislai Orichovii Okszii. Adiunximus Vitam Petri Kmitae. - Dobromoli: In officina Ioannis Szeligae, 1611. - [7] k., 312 [i.e. 302] s., [2, ost. cz.] k.; 8º Estr., t. 23, s. 444-445. Sygnatura: BZ 7462.

Egzemplarz ma oprawę kartonowa, grzbiet i rogi okładki są skórzane. $\mathrm{Na}$ grzbiecie naklejka z tłoczonymi złotymi napisami (tytuł dzieła) oraz druga, z sygnatura. Grzbiet zdobią złote tłoczenia w formie ornamentów roślinnych. Wyklejka „marmurkowa”. Na wyklejce znajduje się naklejka - ekslibris „BIBLIOTEKA ZAHINIECKA”, co jest oznaką przynależności do księgozbioru Urbanowskich i Starzyńskich. Blok barwiony, koloru czerwonego. Stan zachowania dobry. Na stronie tytułowej zakreślono podpis właściciela. Na stronach 306-307 znajdują się plamy z atramentu.

7. [Solikowski Jan Dymitr]: Stanislai Orechovii Apocalipsis... - Leopoli: [Jan Szeliga], 1630. - [28, ost. cz.] k., 1 tabl. 1; 4. Estr., t. 29, s. 38, T. 8, s. 199 [Orzechowski]. Sygnatura: Mniszech.

Egzemplarz ma uszkodzoną okładkę. Oprawa kartonowa, grzbiet wykonany ze skóry. Na wyklejce ekslibris - znakiem przynależności do księgozbioru Mniszchów. Przed stroną tytułową znajduje się pięć czystych kart. Na stronie tytułowej podpisy Stanisława Mniszcha. Na ostatniej stronie tekstu notatka datowana na rok 1772, informująca o tym, że 
książka należy do biblioteki zakonu klasztoru karmelitów w Wiśniowcu. Po tekście wszyta karta z rycina. W końcu sześć czystych kart. Egzemplarz wymaga restauracji.

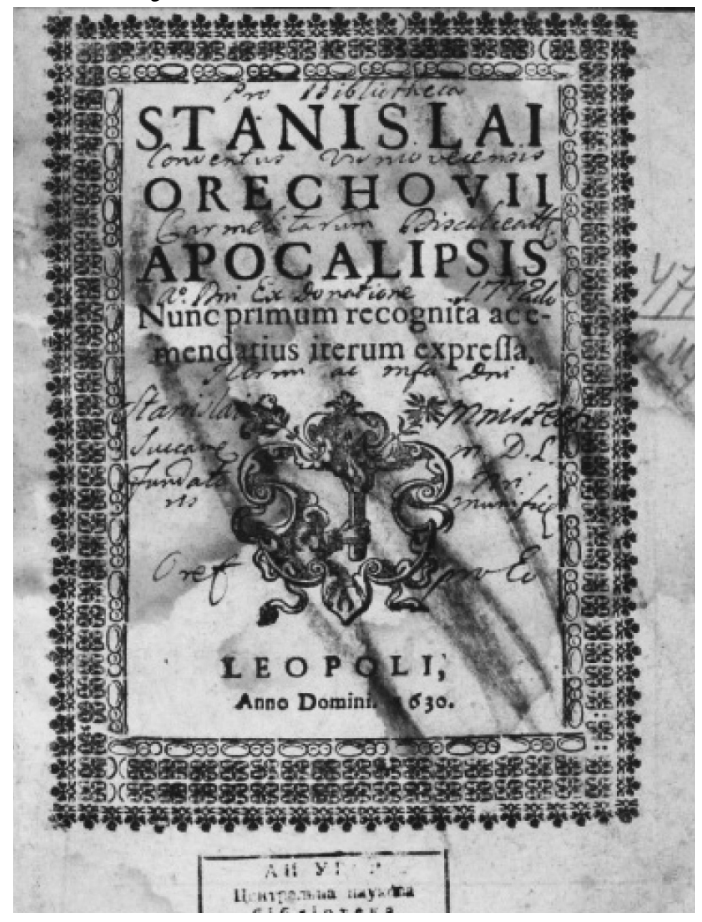

8. Stanislai Orichovii Roxolani Fidelis Svbditvs Siue De Institvtione Regia ad Sigismundum Augustum Libri duo. - Cracoviae: ex officina typographica Francisci Caesarij. - [po 5 I 1639] - [8], 80 s.; 4º . Nb. przedmowa do Stanisława Lubomirskiego dat. 5 I 1639 r. Estr., t. 23, s. 456-457.

Egz. a: Sygnatura: S. J. 492.

Egzemplarz ma uszkodzoną oprawę i arkusze zewnętrzne. Oprawa jest kartonowa, grzbiet ze skóry. Na wyklejce napis z sygnaturą książki. $\mathrm{Na}$ stronie tytułowej napis łaciński świadczący o przynależności egzemplarza do biblioteki krzemienieckiego kolegium jezuickiego, datowany na 1736 r. Na ostatniej stronie tekstu nieczytelne napisy wykonane czarnym atramentem. W książce znaleziono kartkę, na której czarnym atramentem napisano objaśnienia do tekstu. Charakter pisma równy, czytelny.

Egz. b: Sygnatura: Coll. Jabl. 727.

Egzemplarz jest drugim adligatem w klocku. Oprawa, jak i w większości dzieł w bibliotece Jabłonowskich, zrobiona jest ze skóry cielęcej. $\mathrm{Na}$ 
okładce - naklejka z sygnatura. Wolumin ma uszkodzone ostatnie strony. Żadnych notatek nie zawiera.

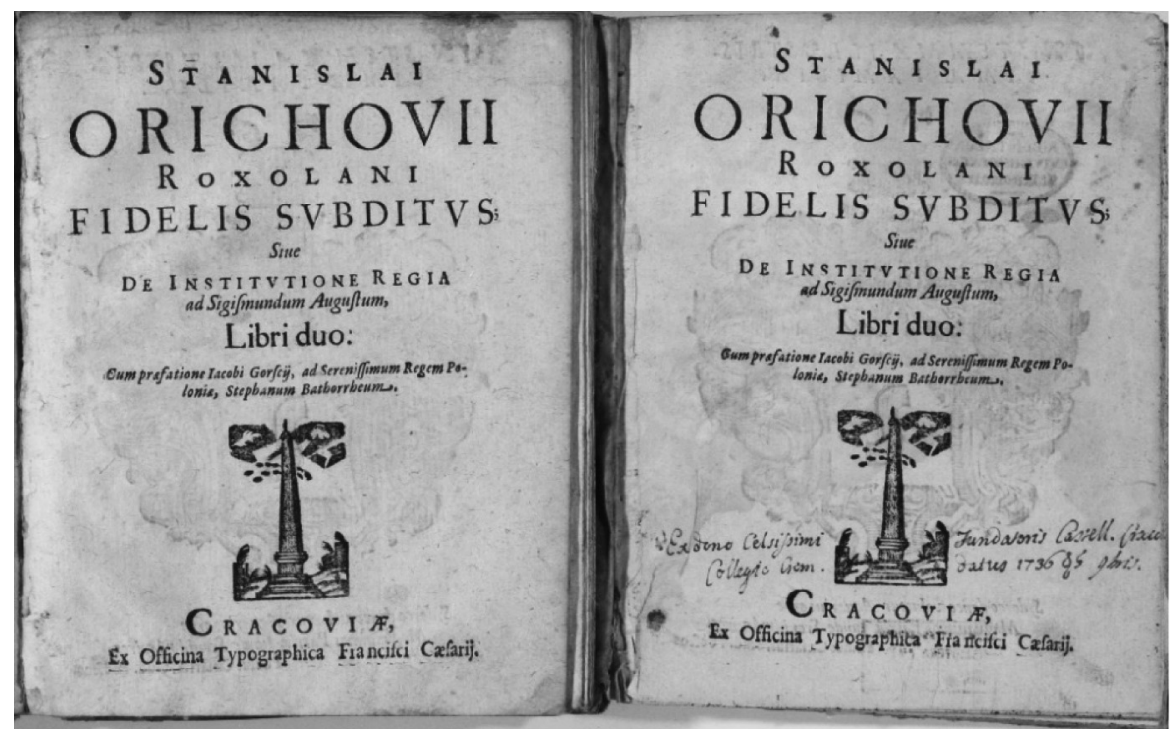

9. Annales Stanislai Orichovii Okszii. Adiunximus vitam Petri Kmitae. - Dantisci: apud Georgium Forsterum, 1643. - [4], [2], [4], 251 s.; $12^{\circ}$. Estr., t. 23, s. 445.

Egz. a: Sygnatura: Reg. X. 1051.

Egzemplarz ma kartonową oprawę. Na ma stronie przedtytułowej wypisana ołówkiem sygnatura. Na wyklejce i stronie tytułowej (również z drugiej strony) liczne podpisy wykonane ołówkiem i czarnym atramentem. U dołu strony przedtytułowej owalna pieczatka koloru niebieskiego „Библиотека университета Св. Владимира” (Biblioteka Uniwersytetu św. Włodzimierza).

Egz. b: Sygnatura: Берд. кол. 2376.

Egzemplarz ma kartonową oprawę, grzbiet jest wykonany ze skóry. $\mathrm{Na}$ wyklejce napis sporządzony czerwonym ołówkiem: „1650” oraz atramentem: „1699”. Na stronie tytułowej u góry wypisana sygnatura, pomiędzy linijkami tytułu znajduje się napis świadczący o przynależności książki do biblioteki berdyczowskiego klasztoru karmelitów bosych. Stan zachowania dobry.

10. Subditus fidelis Stanislai Okszyc Orzechowski Roxolani. Quondam ad Sigismundum Augustum I. Nunc ad Serenissimum Augustum II 
in obsequium Sacrae R. M. a Fr. Pavlo Antonio Radzynski Gvardiano Sanocensi Ordinis Minorum Sancti Francisci Conventualium destinatus. - Varsaviae: typis Collegij Scholarum Piarum, 1698. - [6] k., 88 s.; 4. Estr., t. 23, s. 457. Sygnatura: Coll. Jabl. 1001.

Oprawa ze skóry cielęcej. Na okładce naklejka z sygnaturą. Blok barwiony na kolor czerwony. Na wyklejce wypisana ołówkiem sygnatura. Stan zachowania dobry.

11. Stanislai Okszyc Orzechowski... Fidelis subditus Sive De Institvtione Regia ad Sigismundum Augustum Libri II. Tum jdea Apocaliptica Ejusdem Orichovii [właśc. Jana Dymitra Solikowskiego]. - Varsaviae: typis S. R. M. et Reipublicae in Collegio Scholarum Piarum, 1763. - [5], 98, 82 s.; $4^{\circ}$. Nb. accedit z własną k. tytułowa. Estr., t. 23, s. 457, T. 29, s. 39 [Solikowski]. Sygnatura: Reg. X. 318/1, Reg. X. 318/2.

Egzemplarz ma oprawę kartonowa, grzbiet i rogi skórzane. Blok barwiony na kolor czerwony. Nastronie przedtytułowej znajduje się wypisana ołówkiem sygnatura. Na stronie tytułowej owalna pieczątka koloru fioletowego „Библиотека университета Св. Владимира” (Biblioteka Uniwersytetu św. Włodzimierza).

12. Zywot y Smierc Jana Tarnowskiego kasztelana krakowskiego hetmana wielkiego koronnego pisany niegdyś przez Stanisława Orzechowskiego... - w Warszawie: w Drukarni J. K. Mci y Rzeczypospolitej w Koll. Soc. Jesu, 1773. - 125 s.; $8^{\circ}$. Estr., t. 23, s. 458-459. Sygnatura: 1851/598.

Egzemplarz ma miękką oprawę kartonową koloru błękitnego. $\mathrm{Na}$ okładce i stronie tytułowej znajduje się wypisana ołówkiem sygnatura. $\mathrm{Na}$ niektórych stronach ślady wilgoci. Stan zachowania - zadowalający.

13. [Solikowski Jan Dymitr] Sen Na Jawie Albo Widowisko Stanisława Orzechowskiego w Ktorym Postawa Zamieszaney y Uciemięzoney Rzeczypospolitey, Tudzież Naprawienia iey Sposob Okazuie się, Przez M. Zygmunta Alexandra Włyńskiego... z Łacinskiego na Polskie Przethumaczone... - W Warszawie: W Drukarni Nadworney J.K.Mci, 1779. - [4], 84, [1] s.; 8. Estr., t. 29, s. 39, t. 9, s. 476 [Orzechowski].

\section{Egz. a. Sygnatura: XXI 6/67.}

Egzemplarz ma miękką oprawę kartonową koloru błękitnego. Brak przedniej okładziny okładki. Na stronie tytułowej naklejka z sygnatura. Sygnatura wypisana także ołówkiem. Na niektórych stronach widoczne ślady wilgoci. Wymaga restauracji. 
Egz. b. Sygnatura: Reg. X. 172.

Egzemplarz ma miękką oprawę kartonową koloru zielonego. Na wyklejce napisana ołówkiem sygnatura oraz owalna pieczątka koloru fioletowego „Библиотека университета Св. Владимира” (Biblioteka Uniwersytetu św. Włodzimierza). Stan zachowania zadowalający.

14. Stanisława Okszyca Orzechowskiego Kroniki Polskie od zgonu Zygmunta Igo. Edycya Tadeusza Mostowskiego. - Warszawa: w Drukarni Nro 646, 1805. - 482 s., 20 cm, Estr., XIX, t. 3, s. 317.

\section{Egz. a. Sygnatura: Із пол. В 4311.}

Egzemplarz ma oprawę kartonową, grzbiet i rogi skórzane. Okładka jest uszkodzona. Na ostatniej stronie tekstu i tylnej wyklejce znajdują się prostokatne pieczątki koloru fioletowego „Дез. 1937 p” (Dez. 1937 r.). Oznaczeń kolekcji brak.

\section{Egz. b. Sygnatura: Із пол. В 1417/24.1.}

Egzemplarz ma oprawę kartonowa, grzbiet i rogi skórzane. Na grzbiecie znajdują się złote tłoczenia tytułu i tomu dzieła. Oprawa jest uszkodzona. Na stronie tytułowej podpis „Z Biblioteki...” (dalej nieczytelne). W książce umieszczono portret Zygmunta Augusta. Na dolnej wyklejce ekslibris z napisem „De la Bibliotheque de Jean Nepomucen Giżycki”.

15. Życie Jana Tarnowskiego kasztelana krakowskiego, hetmana wielkiego koronnego pisane niegdyś przez Stan. Orzechowskiego... wydrukowane i przypiskami objaśnione przez Fr. Bohomolca. Wyd. nowe Jana Nep. Bobrowicza. - Lipsk: Breitkopf \& Haertel, 1837. - 317, [1] s., portr. - (Życia stawnych Polaków; t. 4). Estr., t. 10, s. 167. Sygnatura: Із пол. B 1170/4.

Egzemplarz ma oprawę kartonowa, okładka pokryta ciemną tkaniną. $\mathrm{Na}$ stronie tytułowej podpis właściciela „Zygmunt Marinowski”. Egzemplarz jest pierwszym adligatem $\mathrm{w}$ klocku. $\mathrm{Na}$ frontispisie umieszczono portret Jana Sapiehy. Stan zachowania - dobry.

16. Dyalog albo rozmowa około exekucyi Polskiej Korony przez Stanisława Orzechowskiego. Wydanie Kazimierza Józefa Turowskiego. Kraków: nakładem Wydawnictwa Biblioteki Polskiej, 1858. - 106, IV s.; 20 cm. Estr. T. 10, s. 330. Sygnatura: 1864/904.

Egzemplarz ma oprawę kartonową, nieznacznie uszkodzoną. $\mathrm{Na}$ okładce znajdują się sygnatury napisane czerwonym ołówkiem i czar- 


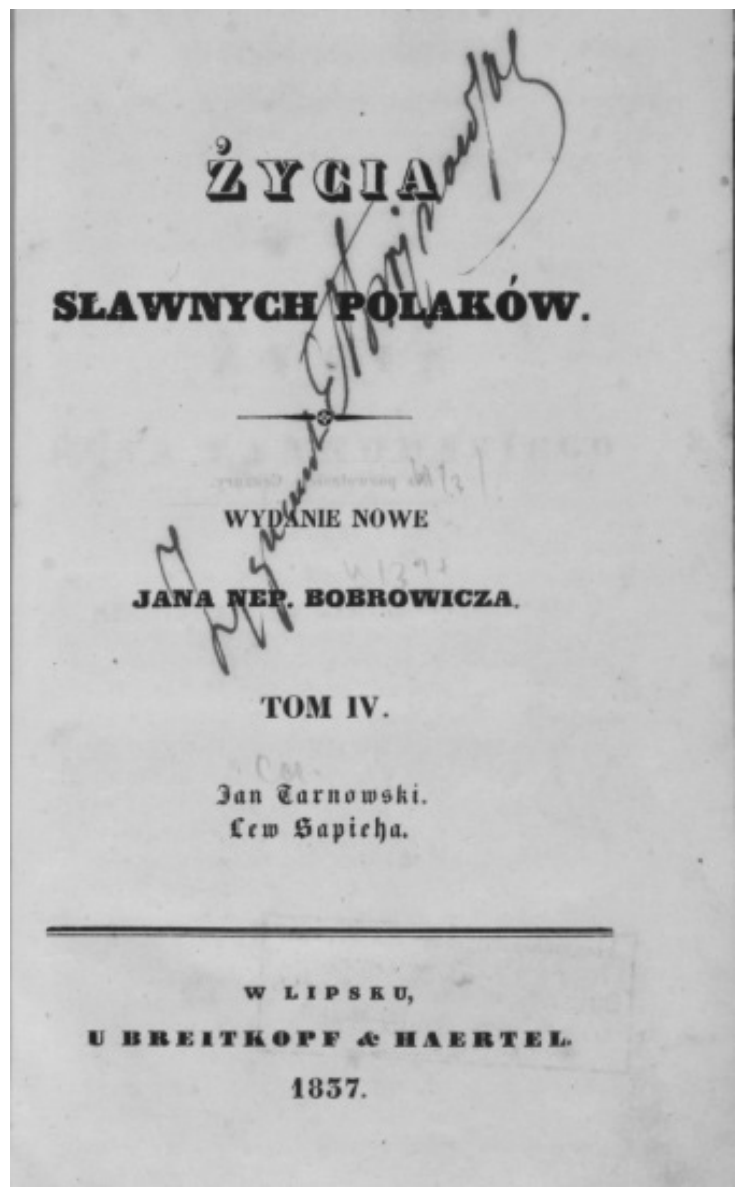

nym atramentem. Na odwrocie strony tytułowej owalna czarna pieczatka z napisem „BIBLIOTHECA UNIVERSITATIS S. VLADIMIRI".

Podsumowując, należy stwierdzić, że druki dzieł S. Orzechowskiego były dość rozpowszechnione $w$ pewnych kręgach ludzi wykształconych. Prawie w każdej lepiej znanej prywatnej bibliotece, która obecnie znajduje się $\mathrm{w}$ zasobie WBZIK, znajdowało się po kilka egzemplarzy wydań znanego polemisty. Choć dziś można dyskutować na temat tego, jak odnosili się właściciele książek do ich treści, ale chyba jednak najważniejsze jest to, że dzięki takim właśnie bibliotekom możemy obecnie obcować z dziełami, które nie utraciły na aktualności przez ostatnie kilkaset lat.

Pracownicy NBUW przygotowują wystawę elektroniczną, poświęconą 500-leciu urodzin S. Orzechowskiego. Oprócz tego szereg jego dzieł skierowano do digitalizacji i zamieszczono na stronach internetowych Biblioteki. Mamy nadzieję, że publikacja w formie cyfrowej pomoże w popularyzacji zarówno osoby jak i prac Stanisława Orzechowskiego.

thum. Katarzyna Łoza 